\title{
Bare NP's, Reference to Kinds, and Incorporation
}

\author{
Veneeta Dayal \\ Rutgers University
}

\section{Number Marking in Hindi Bare NP's}

This paper deals with differences between Hindi bare nominals in the availability of existential readings and the possibility of discourse anaphora. Hindi bare singulars are more restricted than bare plurals in both respects. These differences are discussed in light of two questions that are of relevance beyond the facts of Hindi. Is reference to kinds a mediating factor in object level quantification of bare nominal expressions? How does the semantics of bare nominals interact with incorporation?

The description of the core facts is based on earlier work (Dayal 1992 and Porterfield and Srivastav 1988). Hindi bare nominals have a variety of readings which can be described in terms familiar from Carlson's 1977 discussion of bare plurals. (1) and (2) show that both the bare singular and the bare plural are compatible with kind level predicates, establishing their status as kind denoting:

a. kutta aam jaanvar hai dog common animal be-PR

'The dog is a common animal.'

b. common-animal( $\left({ }^{\mathrm{d}} \mathrm{dog}\right)$

a. kutte yehaaN aam haiN dogs here common be-PR 'Dogs are common here.'

b. common( $($ dogs $)$

Turning to object level predicates, we first consider sentences with imperfective aspect. Imperfective aspect implies a regularity of occurrence, leading to a generic reading. This can be captured by treating aspect as contributing a generic operator which can bind individual instantiations of the kind, as in (3b)-(4b):
a. kutta bhauNktaa hai dog bark-PR 'The dog barks.'
b. $\operatorname{GENx}\left[{ }^{\mathrm{u}} \operatorname{dog}(\mathrm{x})\right][\operatorname{bark}(\mathrm{x})]$
c. $\operatorname{bark}(\operatorname{lx}[\operatorname{dog}(\mathrm{x})])$
a. kutte bhauNkte haiN
dogs bark-PR
'The dogs/Dogs bark.'
b. $\operatorname{GENx}[\operatorname{un} \operatorname{dogs}(\mathrm{x})][\operatorname{bark}(\mathrm{x})]$
c. $\operatorname{bark}(\operatorname{lx}[\operatorname{dogs}(\mathrm{x})])$ 
These sentences have an additional habitual reading. This can be represented by means of the iota operator which encodes the uniqueness associated with definites. (3c)-(4c) attribute the habit of barking to the unique dog or the unique maximal set of dogs in the context. We see, then, that Hindi bare nominals differ from English bare nominals in admitting a definite reading. Intuitively, this correlates with the fact that Hindi does not have a lexical definite determiner. ${ }^{1}$

(5)-(6) also involve object level predicates but they are in progressive aspect, denoting a single on-going action. Here too the iota operator captures the relevant reading. They also appear to have indefinite readings due to existential quantification over individual instantiations of the kind term:
a. anu kitaab paRh rahii hai
Anu book read-PROG-PR
'Anu is reading the book/a book.'
b. $\operatorname{read}(\mathrm{a}, \mathrm{ix}[\operatorname{book}(\mathrm{x})])$
c. $\exists \mathrm{x}[\operatorname{un} \operatorname{book}(\mathrm{x}) \& \operatorname{read}(\mathrm{a}, \mathrm{x})]$
a. anu kitaabeN paRh rahii hai
Anu books read-PROG-PR
'Anu is reading the books/books.'
b. $\operatorname{read}(\mathrm{a}, \mathrm{ix}[\operatorname{books}(\mathrm{x})])$
c. $\exists \mathrm{x}[\operatorname{un} \operatorname{books}(\mathrm{x}) \& \operatorname{read}(\mathrm{a}, \mathrm{x})]$

(7)-(8) further establish the parallel between Hindi and English bare nominals. The bare nominal, we see, obligatorily takes scope under negation. This contrasts with regular indefinites that permute with negation. In the interests of space I only compare singular terms but essentially the same facts hold for the plural case. Bare nominals also differ from regular indefinites in not interacting scopally with other quantifiers though I do not give examples here:

a. anu kitaab nahiiN paRhegii

Anu book not read-F

'Anu won't read any book.' not 'There's a book Anu won't read.'

b. anu ek/koii kitaabnahiiN paRhegii

Anu one/some book not read-F

'Anu won't read any book.' and 'There is a book Anu won't read.'

(8) shows that a bare nominal takes scope under an adverbial, leading to a pragmatically plausible reading, while a regular indefinite has scope over it:

a. anu puure din machhlii pakaRtii rahii

Anu whole day fish catch-PAST

'Anu kept catching fish the whole day.'

b. anu puure din ek machhlii-ko pakaRtii rahii

Anu whole day one fish-ACC catch-PAST

'Anu kept catching a fish the whole day.' 
So far, then, Hindi and English bare nominals align except for two differences. One, Hindi bare nominals can be singular or plural and Hindi bare nominals have an additional definite reading. Things become more interesting when the two languages diverge. The first difference surfaces when bare singulars occur in the subject position of sentences with an episodic interpretation. The bare plural behaves in the expected way, allowing the existential reading. The bare singular, on the other hand, is resistant to this interpretation: ${ }^{2}$
a. bacca khel rahaa hai
kid play-PROG-PR
'The $\mathrm{kid} / *^{*}$ a kid is playing.'
b. bacce khel rahe haiN
kids play-PROG-PR
'The kids/(Some) kids are playing.'

The parallelism between English and Hindi also breaks down with respect to discourse anaphora. Again, it is the bare singular that behaves unexpectedly:

anu kitaab paRh rahii hai. *vo bahut acchii hai

Anu book read-PR-PROG It very good be-PR

'Anu is reading a book. It is very good.'

Based on these data, I concluded in Dayal 1992 that Hindi bare nominals are ambiguous between definite and kind-denoting terms. They are not indefinites, their existential readings being dependent on kind reference. I further argued that singular kind formation differs from plural kind formation in requiring the kind term to be atomic. This has the effect of barring semantic operations access to individual instantiations of the singular kind, but not of the plural kind. The existential reading of singular kinds then cannot be derived on the basis of the lexical-aspectual specifications of the verb. The subject-object asymmetry is due to the fact that the existential reading arises in the context of noun incorporation. Finally, I claimed that the incorporated nominal does not introduce a discourse referent, thereby explaining the absence of discourse anaphora. Instead, it involves a complex property where the verb combines with the singular kind. That is, the logical representation of (10) is $B O O K-\operatorname{read}(a)$ not $\exists x[\operatorname{book}(x) \& \operatorname{read}(a, x)]$. In this paper, I do not depart substantively from these claims. However, I believe they raise issues that bear further scrutiny. The rest of this paper is devoted to exploring some of these issues.

2. Reference to Kinds in Object Level Quantification

\subsection{Restriction on $\exists$-readings of Bare Singulars}

We have seen above that the facts of Hindi are amenable to an explanation in terms 
of a kind based approach but we might go a bit further and ask whether the data force such an approach on us. There are at least three arguments suggesting that they do.

Consider the alternative DRT-based approaches to object level quantification for bare nominals, such as Wilkinson 1991, Gerstner and Krifka 1993, Kratzer 1988, Diesing 1988. In these approaches bare plurals are conflated with (singular) indefinites and this is motivated by the observation that indefinites and bare plurals vary in quantificational force in the same contexts. Both are taken to be indefinites introducing variables which are bound by a generic or existential quantifier, depending on the lexical-aspectual properties of the verb and/or the focus structure of the sentence. This seems a natural enough move obviating the need to posit differences in the denotations of the two NP's beyond taking bare plurals to be ambiguous between kinds and indefinites. Now this is where a language like Hindi becomes important. The DRT-based approaches predict parallels between bare singulars and bare plurals all the way, but we have seen that this is not the case.[In the earlier papers I give examples of other contexts where the behavior of the Hindi bare singular diverges from that of the English singular indefinite.]

The kind based approaches to bare nominals do better because they have extra semantic operations where sensitivity to number marking can play a role:

a.

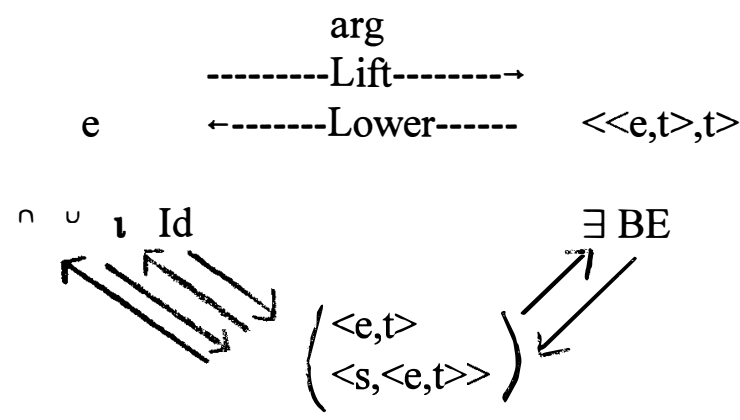

b. ${ }^{n} \mathrm{P}=\lambda \mathrm{s} \mathfrak{} \mathrm{P}_{\mathrm{s}}$, if it is in $\mathrm{K}$ (ind), undefined otherwise.

For example, the way Chierchia 1998 defines nom, the operation that takes a predicate expression to the corresponding kind term imposes the totally implausible requirement on singular kinds that they be uniquely instantiated in every world. In fact, Chierchia then proposes ways for overcoming this problem to account for the definite singular generic in English. What I claim instead is that we accept the consequences and take nom to be undefined for singular terms. We can then use this atomicity constraint imposed by singular number on the nominal to rule out object level quantification for bare singulars in Hindi. Of course, this will not solve the whole problem since the readily available generic readings of singular kinds would have to be accounted for, as would their existential readings which are also possible, at least in Hindi, albeit to a limited extent. ${ }^{3}$ The point here is simply that a kind based approach can drive a wedge between NP's based on number marking, which is what we seem to need for the case at hand.

Before moving on to the second argument in favor of kinds, I would like to clarify that although I block kind formation via nom for singular terms, I recognize 
singular kinds in natural language as lexical primitives, on a par with common nouns like team or committee (see Barker 1992 and Schwarzschild 1996 for discussion). The key idea behind this is that they are conceptually plural but gramatically singular and do not allow predication to individuals that we intuitively consider their instantiations. Here I use capitals to refer to such atomic singular kinds to distinguish them from kinds formed via nom.

\subsection{Lack of Implicatures with $\exists$-readings of Bare Singulars}

The second argument for recognizing kinds in the derivation of object level readings of bare NPs comes from contexts where bare singulars admit existential readings. These are the object position of episodic statements such as $(5 \mathrm{a})$, repeated below:
a. anu kitaab paRh rahii hai
Anu book read-PROG-PR
'Anu is reading the book/a book.'
b. BOOK-read(a)
c. $\exists x[\operatorname{book}(\mathrm{x}) \& \operatorname{read}(\mathrm{a}, \mathrm{x})]$

Though the bare nominal is singular, the sentence carries no implicature that only one book was read. Referring to singular kinds, as in (12b), may provide a better explanation for this than treating the bare nominal as a simple indefinite as in (12c).

I should note that the same intuition about absence of number implicatures has been noted for incorporated nominals in Greenlandic (Bittner 1994, Van Geenhoven 1996) who assign logical forms like (12c) for those structures. One important difference between Hindi and Greenlandic, however, is that in Greenlandic the stem of the nominal is neutral with respect to number, with plural and singular morphemes disambiguating the full NP in one direction or the other. Since it is the stem that gets incorporated, representations like (12c) do not involve any commitment to singular or plural individuals. In Hindi, on the other hand, the form we have in (12) behaves like a singular term in every other context. For example, (12a) under its definite reading would denote a single contextually salient book. And the singular-plural distinction shows up in combination with determiners and in predicative positions in a manner similar to English. This suggests an analysis of the singular common noun in Hindi as denoting a set of atoms, with plurals denoting its closure under sum formation (with a possible subtraction of the atoms):
a. har/ek laRkaa; do/kaii laRke every/a boy two/several boys
b. har/ek ghar; do/kaii ghar every/a house two/several houses
c. har/ek laRkii; do/kaii laRkiyaaN every/a girl two/several girls
d. har/ek kitaab; do/kaii kitaabeN every/a book two/several book

masculine nouns feminine nouns 


\section{a. anu lekhikaa hai}

Anu writer is

'Anu is a writer.'

b. anu aur ramaa lekhikaayeN haiN

Anu and Rama writers are

'Anu and Rama are writers.'

In light of these facts, it is not obvious why the interpretation of the singular terms should not be restricted to atoms in incorporated structures. Reference to singular kinds in representing the incorporated reading provides a way of resolving the dilemma between grammatical singularity and plural interpretation.

\subsection{Interaction between Type Shifts}

Finally, there is an argument for kinds to be made by examining differences between Hindi and English bare plurals when they cannot denote kinds. Carlson 1977 noted for English that such bare plurals do not display the frozen scopal properties of kind denoting bare plurals. However, Hindi bare plurals always remain scopally frozen.

The explanation for this difference hinges on a particular account of the English facts proposed by Chierchia 1998. In his view the type shift operators discussed by Partee 1987 are not freely available repair options but are subject to licensing conditions. So, for example, if a language has a lexical determiner which encodes a particular type shift meaning, that type shift will not be available as a covert option in that language. This blocking principle, we see, readily explains the fact that English bare plurals lack the definite reading that Hindi bare plurals have. In (16a), the bare plural cannot get a definite reading via iota because of the existence of the in English; the corresponding Hindi case in (16b) poses no problems since the absence of a definite article in Hindi makes iota available:

\section{Blocking Principle (Type Shifting as Last Resort):}

For any type shifting operation $\tau$ and any $\mathrm{X}: * \tau(\mathrm{X})$ if there is a determiner $D$ such that for any set $X$ in its domain, $D(X)=\tau(X)$.

a. Some children came. $^{*}$ Children $_{\mathrm{i}}$ were happy.

b. kuch bacce aaye. bacce $_{i}$ bahut khush lage some children came children very happy seemed 'Some children came. The children seemed very happy.'

Let us turn now to bare plurals that are not kind denoting. (17a) shows that parts of this machine is not compatible with true kind predication, presumably because the definite inside the NP would force the kind to be instantiated by the same entities in all worlds. (17b) shows that this bare plural can interact with negation. The contrast is with cases like (18) where possibility of kind reference results in the loss of scope interaction. According to Chierchia, this is because nom, a simpler type shift than the existential, is able to block it: 
a.* Parts of this machine are widespread.

b. John didn't see parts of this machine.

c. $\exists \mathrm{x}[$ parts-of-this-machine $(\mathrm{x}) \& \neg(\operatorname{see}(\mathrm{j}, \mathrm{x}))]$ and

d. $\neg \exists x[$ parts-of-this-machine $(\mathrm{x}) \& \operatorname{see}(\mathrm{j}, \mathrm{x})]$ )

a. Spots on the floor are a common sight.

b. John didn't see spots on the floor.

c. $\neg \exists \mathrm{x}[$ spots-on-the-floor(x) \& see(j,x)]) but not

d. $\exists x$ [spots-on-the-floor $(x) \& \neg(\operatorname{see}(\mathrm{j}, \mathrm{x}))$ ]

Turning to Hindi, (19a) shows that the bare plural is not compatible with true kind predication for the same reasons as English. (19b) shows, however, that the bare plural does not admit a wide scope existential reading. It only has the scopally frozen reading that interaction of pred and nom with verbal semantics yields:
a.* is mashin ke TukRe aam haiN
this machine of parts common are
'Parts of this machine are common.'
b. anu-ne is mashiin ke TukRe nahiiN dekhe
Anu-ERG this machine of parts not see-P
'Anu didn't see any/the parts of this machine.'
c. $\neg \exists \mathrm{x}[\mathrm{p}-\mathrm{o}-\mathrm{t}-\mathrm{m}(\mathrm{x}) \& \operatorname{see}(\mathrm{a}, \mathrm{x})]$ but not
d. $\exists x[\mathrm{p}-\mathrm{o}-\mathrm{t}-\mathrm{m}(\mathrm{x}) \& \neg \operatorname{see}(\mathrm{a}, \mathrm{x})]$
e. $\neg \exists \mathrm{x}[\mathrm{p}-\mathrm{o}-\mathrm{t}-\mathrm{m}(\mathrm{x}) \& \operatorname{see}(\mathrm{a}, \mathrm{x})] \equiv \neg \operatorname{see}(a, \mathfrak{\imath x}[p-o-t-m(x)])$.

The solution to the puzzle is quite simple. We have already seen that iota is freely available in Hindi and given the kinship between iota and nom, it too can be considered the simpler type shift for turning predicative expressions into arguments. As (19e) shows what appears to be the frozen existential reading could well be the definite reading of a sentence with negation. I should note here that though this seems to follow directly from Chierchia's system, it is not the conclusion he himself comes to in relation to Russian, a language typologically similar to Hindi in having number marking but no definite article. If iota and the existential type shifts are indeed freely available in Russian, as Chierchia claims, it would require a rethinking of the interaction between covert type shifts. The facts from Hindi, however, support the view of type shifts he presents. ${ }^{4}$ I will assume, then, that the blocking effects we have seen here add to the evidence in favor of reference to kinds and leave discussion of possible differences between Russian and English to another occassion.

\section{Hindi Incorporation}

\subsection{Core Features of Hindi Incorporation}

Summarizing so far, we have established that Hindi bare nominals in argumental positions refer to kinds or to contextually salient maximal entities. Bare plurals are 
able to have existential readings by the application of pred to the kind term. This is not possible for bare singulars since they are atomic in nature. The only way they can have existential readings is by incorporating with the verb. The goal of this section is to explicate exactly how this incorporated existential reading comes about.

I will begin by putting Hindi incorporation in perspective. The claim that Hindi has incorporation is somewhat surprising since there is no discernible morphological fusion involved. Nevertheless, there are two respects in which the Hindi structures align with what we know about noun incorporation from Mithun 1984 and Baker 1988, for example. One, it is well known that the direct object is the typical target of incorporation and the original motivation for positing incorporation in Hindi was precisely the adjacency requirement for existential readings of bare singulars (cf. (20a)-(20b)). In fact, the adjacency requirement is even stricter. In (20c) Accusative case marking on the verb blocks the existential reading:
a. bacca khel rahaa hai
kid play-PROG-PR
'The kid/*a kid is playing.'
b. anu kitaab paRh rahii hai
Anu book read-PROG-PR
'Anu is reading a book.'
c. anu kitaab-ko paRh rahii hai
Anu book-ACC see-PROG-PR
'Anu is reading the/*a book.'

Another respect in which Hindi patterns with what we know about incorporation is in restrictions on possible combinations. Generally speaking, it is much easier to incorporate inanimate themes than animate ones. The set in (21a) is acceptable but those in (21b) are not. At an impressionistic level, one can say that it is relatively hard to come up with animate objects that are incorporated. With inanimate objects the situation is the reverse. It is very easy to extend the list of incorporated nominals in (21c). In fact, it is only in certain contexts that it even becomes evident that there are restrictions on incorporated inanimates. For example, there seems to be a contrast between the plural and the singular in (22), suggesting that there is a constraint on incorporation rather than any pramatic awkwardness:
a. laRkii dekhnaa; baccaa sambhalnaa; makkhii maarnaa
GIRL-seeing CHILD-managing FLY-beating
b. *aurat dekhnaa; *baccaa maarnaa; *biwii maarnaa; *kutta maarnaa WOMAN-seeing; CHILD-beating WIFE-beating; DOG-beating
c. kitaab-paRhnaa; baal kaaTnaa; kapRa silnaa; kapRaa kaaTnaa; BOOK-reading; HAIR-cutting; CLOTH-sewing CLOTH-cutting
a. anu puure samai kitaabeN pheNktii rahii
'Anu kept throwing books the whole time.'
b. * anu puure samai kitaab pheNktii rahii
'Anu kept throwing book the whole time.' 
It is worth noting here that it is not a lexical property of a particular verb or nominal whether it can participate in incorporation. dekhnaa 'to see', for example, incorporates with laRkii 'girl' but not aurat 'woman'. Similarly, bacca 'child' lends itself to incorporating with a verb like sambhaalnaa 'to manage' but not maarnaa 'to beat'. There is a, perhaps, related point to be made about the semantics of these combinations. Mithun notes that they refer to some kind of well-established activity. The intuition behind this can be brought out more clearly by discussing the case of animate objects. laRkii dekhnaa 'girl seeing' cannot be used to describe a situation in which one is sitting by the window watching people go by, some of whom happen to be girls. Rather, it refers to the act of looking at prospective brides with the purpose of arranging a marriage. And there is a certain amount of idiosyncrasy typically associated with lexical processes. There is no logical reason that laRkii dekhnaa should be acceptable but not aurat dekhnaa 'woman seeing'.

Based on these correlations we would classify Hindi as having incorporation but it lacks one classic property of incorporation. The Hindi verb remains transitive and the nominal retains its syntactic status as complement:

\section{a. anu-ne (har) kitaab paRhii \\ Anu-ERG (every) book read-P \\ 'Anu read every book/a book.' \\ b. anu-ne (har) kitaab-ko uThayaa \\ Anu-ERG (every) book-ACC pick-up-P \\ 'Anu picked up every book/the book.'}

Assuming that full quantified NP's do not inçorporate we may take structures like (23) to involve incorporation only when there is no universal determiner or case marking. These sentences have a transitive verb which in the simple past triggers ergative case on subject. Hindi verbs agree with the highest nominative marked object. In (23a), the verb shows feminine gender regardless of whether the nominal is a quantified NP or an incorporated nominal. It does not show the default masculine agreement that we see in (23b) where both nominals are case marked. The incorporated nominal must be an argument of the verb for purposes of agreement.

Although the syntactic visibility of the nominal suggests that Hindi does not have incorporation at the syntactic level, it has been argued for at some length by Mohanan 1995. She posits two complementation structures for Hindi, one with $\mathrm{N}$ and V under V, as in (24a), for incorporation and one with NP and V under VP, as in $(24 b)$, for regular complementation: ${ }^{5}$
a. [vp [v [N laRkii] [v dekhnaa $]]]$ girl-NOM seeing
b. [ ${ }_{\mathrm{VP}}[\mathrm{NP}$ laRkii-ko ] [v dekhnaa $\left.]\right]$ girl-ACC seeing

While two different positions for direct objects have a certain currency, I am not convinced that it addresses the problem of Hindi incorporation fully. For example, 
Mohanan takes the possibility of sentential negation to be a test for regular complementation but this leads to incorrect predictions in cases like (7a), repeated below. If bare nominals are regular indefinites, as she takes them to be, (25) should allow the existential to have scope over negation but this is clearly not the case:

anu kitaab nahiiN paRhegii

Anu book not read-F

'Anu won't read any book.'

Putting together all the pieces we have collected so far, we can say that Hindi incorporation requires an account in which the nominal does not support anaphora, has existential import not restricted to atoms, and is blocked by case particles but not negation. As we will see next, these features can be delivered by an account where incorporation is treated as essentially a semantic phenomenon.

\subsection{Hindi Incorporation as Theme Suppression}

The proposal I want to make here is that semantic incorporation of the kind we see in Hindi involves a process of theme suppression and it will be useful to demonstrate this with concrete examples. Let us take the verb dekhnaa 'to see', which denotes a relation between individuals, and one that relates to ordinary individuals rather than kinds. Consider what happens when it combines with a bare plural:
a. $\left[[\text { laRkiyaaN }]_{\mathrm{NP}}[\text { dekhnaa }]_{\mathrm{V}}\right]_{\mathrm{VP}}$
"girls seeing"
b. $\lambda y[\operatorname{see}(\mathbf{i x}[\operatorname{girls}(\mathrm{x})])(\mathrm{y})]$
c. $\lambda y\left[\operatorname{see}\left({ }^{n} \operatorname{girls}\right)(y)\right] \Rightarrow \lambda y \exists x\left[{ }^{u n} \operatorname{girl}(\mathrm{x}) \& \operatorname{see}(\mathrm{xs})(\mathrm{y})\right]$

The bare plural is of type $<e, t>$ but since it is in argumental position it is forced to shift to type $e$ either via iota or via nom for the type mismatch to be resolved and functional application to take place. In the first case, we get the definite reading straightforwardly. In the second case, there is a further semantic operation required to adjust the sort mismatch. pred applies to the kind term and alongwith existential binding due to the verbal semantics delivers the existential reading for the object.

Turning to bare singulars, we see that the definite reading is still straightforwardly available, as shown in (27b). However, since nom is undefined for singular terms there is no kind derived existential reading parallel to the plural case:
a. $\left[[\text { laRkii }]_{\mathrm{NP}}[\text { dekhnaa }]_{\mathrm{V}}\right]_{\mathrm{VP}}$
"girl seeing"
b. $\lambda y[\operatorname{see}(\operatorname{lx}[\operatorname{girl}(\mathrm{x})])(\mathrm{y})]$
c. $\lambda y[\operatorname{see}(\operatorname{GIRL})(y)] \Rightarrow \lambda y[G I R L-\operatorname{seeing}(y)]$
d. $\lambda y \exists x[\operatorname{girl}(x) \& \operatorname{see}(x, y)]$

We have, however, another option. The bare singular, in addition to denoting a set of individuals, also denotes the atomic kind GIRL of type $e$. This is of the right type for functional application to take place between verb and object but not of the right 
sort. The verb dekhnaa is a relation involving individuals not kinds and the kind term here does not make available its instantiations. This, I claim, triggers the reanalysis of a 2-place predicate into a complex property, as shown in (27c). This reanalysis, I would like to further claim, requires as a necessary condition that there be a well-established interpretive counterpart where the theme argument is realised by the corresponding predicate and is existentially quantified. The existential import associated with the incorporated nominal is due to the perceived connection between logical representations like (27c) and their interpretive counterparts such as (27d).

Note that this account of incorporation immediately derives most of the features noted earlier. For example, the theme argument does not introduce a discourse referent since it gets suppressed. Consequently there is no antecedent for subsequent discourse anaphora. We also see why the interpretation of an incorporated bare singular is not restricted to atoms. There is no existential quantifier which could be the source of such implicatures. Finally, since incorporation as explicated here is semantically driven, there is no syntactic requirement of adjacency between the verb and its theme argument. The possibility of negation follows.

The problem, of course, is that in giving up structural constraints on incorporation we lose the obvious explanation for the blocking effect of case markers. It turns out, however, that an explanation is available without further stipulation given independently motivated accounts of case marking and the analysis of incorporation as theme suppression. The accusative marker ko, for example, has been argued by Butt 1993 to require the theme argument to denote an entity familiar in the discourse (see the proposal for Turkish in Enç 1991). But note that the semantic requirement introduced by $k o$ can only be satisfied if there is a discourse referent introduced by the theme argument. The secondary predication introduced by accusative marking is clearly fully compatible with the iota shifted meaning of the bare singular, as in (28b). Just as obvious, it is incompatible with incorporation whose chief effect is to suppress that very argument. This is made clear in (28c):
a. anu-ne laRkii-ko dekhaa
Anu girl-ACC saw
'Anu saw the/*a girl.'
b. $\llbracket[$ vp laRkii-ko dekhaa $] \rrbracket=\lambda y[\operatorname{see}(y(\operatorname{lx}[\operatorname{girl}(\mathrm{x})])) \& \operatorname{comgrd}(\mathrm{x})]$
c. $\llbracket[$ vp laRkii-ko dekhaa $] \rrbracket=\lambda y[G I R L-s e e(y) \underline{\&} \operatorname{comgrd}(\mathrm{x})]$

Note that the account does not depend on the particular constraint imposed by case markers, but simply on the fact that case markers require a discourse referent which can be constrained in some way. To appreciate this, consider (29a)-(29c): ${ }^{6}$
a. anu-ne laRkiyoN-ko dekhaa
Anu girls-ACC saw
'Anu saw the/* some girls.'
b. pradhaan mantrii vidyarthiyoN-se miliiN
prime minister students-INSTR meet-PAST
'The prime minister met with (the) students.' 
c. pradhaan mantrii vidyarthii-se miliiN

prime minister student-INSTR meet-PAST

'The prime minister met with the/*a student.'

In (29a) we have a bare plural, which we know can have kind derived existential readings independently of incorporation. However, in this particular case, the existential reading is unavailable. This is because the existential reading is at odds with the requirement of familiarity imposed by accusative marking. In (29b) the object has instrumental case and here the existential reading is available. What we need to determine is whether this is because instrumental case does not block incorporation or because it does not interfere with the kind derived reading. Comparing it to the singular case in (29c), the latter appears to be the case. I am unclear what precisely the instrumental case contributes to meaning but the facts can be explained even with a partial understanding of the phenomenon. Let us assume that instrumental case imposes a trivial requirement on the individual denoted by the NP that it be a member of the domain of individuals. Now, a condition like entity $(x)$ would be compatible with a kind derived reading but not with an incorporated reading. Since bare plurals have the option of a kind derived existential reading while bare singulars can only have incorporated existential readings, the differences between them with regard to accusative and instrumental case is as expected.

Finally, consider what happens when an incorporated nominal is topicalized:

\section{kitaab $_{i}$ anu $t_{i}$ paRhegii}

$\mathrm{BOOK}_{\mathrm{i}}$ Anu $\mathrm{t}_{\mathrm{i}}$ read-F

'A book/Books, Anu will read.'

This sentence is, of course, compatible with the definite reading of the bare nominal. The question of interest here is whether the incorporated existential reading survives and the answer is that it does, under a contrastive reading. This becomes clear if we continue (30) with something like ...akhbaar nahiiN 'A book/Books Anu will read, not a newspaper/newspapers'. Now, nothing in the semantics of incorporation rules out such an object from having an existential reading, but we know that topicalization has its own constraints. Contrastiveness, by satisfying these discourse requirements, brings out the semantically available existential reading.

These details need further elaboration but I hope the discussion here shows that treating incorporation as an essentially semantic phenomenon can handle what appear a priori to be structural constraints. In the next section I would like to turn to more general questions raised by positing theme suppression in the grammar.

\section{Some Consequences of Theme Suppression}

\subsection{Theme Suppression and Anaphora}

Let us begin by asking whether the theme suppression account developed 
for Hindi has cross-linguistic validity. It appears not to apply to Greenlandic incorporation, the one language for which we have formal semantic accounts. Non trivial differences in the syntactic and semantic derivations notwithstanding, Bittner 1994 and Van Geenhoven 1996 both analyse the incorporated nominal as existentially bound. And this captures the fact that it can support discourse anaphora:
a. Aani qimmi-qar-p-u-q. Miki-mik ati-qar-p-u-q
A.ABS dog-have-IND-[-tr]-3sg. M-INST name-have-IND-[-tr]-3sg.
'Aani has a dog. It is called Miki.'
b. $\exists x[\operatorname{dog}(x) \&$ have $(a, x) \&$ called $(x, m)]$

In order to better understand the nature of variation between Greenlandic and Hindi, let us look a bit more closely at the facts. As (32a) shows, incorporated bare singulars do not antecede pronouns but are fully compatible with nominal anaphora. This is in contrast to bare plurals which can antecede pronouns or full nominals: ${ }^{7}$

a. anu apne bete ke liye laRkii dekh rahii hai. vo *uskaa/laRkii-kaa swabhaav jaannaa caahtii hai.

'Anu is girl-seeing for her son. She wants to find out *her/the girl's temperament.'

b. anu apne bete ke liye laRkiyaaN dekh rahii hai. vo unkaa/laRkiyoN-kaa swabhaav jaannaa caahtii hai.

'Anu is seeing girls for her son. She wants to find out their/the girls' temperament.'

The behavior of singular nominals in Hindi is remininscent of nominals in English compounds and unexpressed objects discussed by Postal 1969, Van Geenhoven 1996, Dekker 1993 and Chierchia 1992, among others:

a. I went apple-picking. ${ }^{*}$ They/The apples were sweet.

b. I picked apples. They/The apples were sweet.

c. Jane is baby-sitting. *It/*she/*they/The baby is acting cranky.

d. Jane is looking after kids. They/the babies are acting cranky.

a. The baby has eaten. She seems to have enjoyed *it/the meal.

b. I lost 10 marbles but I found $9 .{ }^{*}$ It/The last marble is under the couch.

In discussing the contrast between Greenlandic incorporation and English compounding, Van Geenhoven suggests that English compounding may have a static existential as opposed to a dynamic one. While this move is plausible enough, it seems to me to shift the problem rather than solve it. One would like to know why some languages or constructions have static existentials as opposed to dynamic ones. Note that given the syntactic visibility of the incorporated nominal in Hindi, we cannot locate static existentials in the lexical component. Note also that the question of an E type interpretation for a pronoun remains open for these constructions. A simple approach to $\mathrm{E}$ type pronouns that treats them like covert definite descriptions 
obviously cannot account for the contrasts in (33) and (34). An approach such as Chierchia 1992, that distinguishes $\mathrm{E}$ type pronouns from (dynamically) bound pronouns in requiring them to have their content syntactically provided goes some way towards explaining the contrast for unexpressed objects. It may even work for compounds since one might say that word boundaries are barriers for syntactic processes, along the lines of Postal 1969. But it would run up against the same problem for Hindi since these objects, we have seen, are visible to the syntax. This is where I think the theme suppression account for Hindi incorporation pays off. If the $E$ type pronoun looks for a salient function, for example from events of seeing to individuals seen, it will not find such a function since incorporation serves precisely to reduce the salience of the theme argument by suppressing it. In the case of bare plurals, there is always the option of a kind derived existential reading so pronominal anaphora is predicted to be possible.

As we saw, an account in terms of word boundaries works for English but cannot be extended to Hindi. A natural question that arises here is whether the theme suppression account developed for Hindi can apply to English compounds. At this point, I do not know enough about compounding to answer this question. I will simply say that this line of inquiry seems worth investigating and if successful would have the appeal of providing a single account for similar effects in both languages.

We began this section by considering two proposals for capturing the meaning of incorporation, one for Greenlandic and one for Hindi, based on differences in their anaphoric properties. Another way of looking at it is to see the anaphora facts as an epiphenomenon reflecting a deeper difference having to do with the suppression or preservation of the theme argument. Mithun 1984 voices an intuition about incorporation that cuts to this point. She notes that "the activity or quality designated by the NV compound is viewed as a recognizable, unitary concept, rather than the chance co-occurence of some action or state and some entity". There has been some debate in the literature whether anaphora is possible in incorporation. Sadock 1986, Bittner 1994 and Van Geenhoven 1996 suggest that it is. Mithun 1984 and 1986, Porterfield and Srivastav 1988, Dayal 1992 and Ramchand 1997 suggest not. In the approach I am suggesting, this debate can be redefined as a debate about the status of the theme. We know that all incorporation structures are not the same morphologically and syntactically. If theme suppression is a dimension along which they can vary, they may not be uniform semantically either.

\subsection{The Semantic and Syntactic Status of the Suppressed Argument}

In this final section I would like to point out a problem with the account of theme suppression presented in section 3.2 and explore an alternative that would keep some of the essential features of incorporation as theme suppression.

I have sugested that the trigger for incorporation is sort mismatch between a singular kind term and the requirements of a verb for an object level theme. In doing so, I made no reference to syntactic structure. The idea was to keep close to regular complementation in order to allow negation to intervene between the verb and the incorporated nominal. The problem that this faces has to do with its applicability to 
a language like English. (35) illustrates the well-known fact that the singular definite generic is restricted to well-established kinds (see Krifa et al 1995). (36) shows that the incorporated bare singular is also restricted (see also Dayal 1992):

a. Green bottles have long necks. ${ }^{*}$ The green bottle has a long neck.

b. Three legged lions are dangerous. $/ *$ The three legged lion is dangerous.

a. anu puraanii kitaab/kitaabeN bectii hai

'Anu sells OLD BOOK/old books.'

b. anu mahangii *kitaab/kitaabeN bectii hai

'Anu sells EXPENSIVE BOOK/expensive books.'

If the English definite singular is the same type of semantic object as the Hindi bare singular, it should allow for incorporated existential readings. Indeed, something arguably like the incorporated reading appears available for (38a)-(38b) (see also Krifka et al 1995). The question is why incorporation does not show up more generally. (38c) clearly lacks the relevant reading:
a. John photographed the grizzly in Africa.
b. We saw the Asian lion on our last tour.
c. We read the book last night.

One option might be to go back to a syntactic account for incorporation along the lines suggested by Mohanan 1995 and say that Hindi differs from English in having N V structures. But this reopens the problem with negation in incorporation. Further, in the absence of independent evidence, it does not do much better than simply saying that one language allows reanalysis to repair sort mismatch and another does not. Instead of taking this line, then, I will explore a somewhat different version of incorporation as theme suppression.

Suppose English only allows full nominal projections in argument position, which must be type $e$ or $\langle\langle e t\rangle t\rangle$. And that Hindi allows NP projections of type $\langle e, t\rangle$ in such positions. Some independent evidence for this might come from copular constructions. In the case of (38a) the bare plural can undergo nom to get its argumental status and then shift back via pred. Functional application can then proceed smoothly. Because the bare singular in (38b) does not have the option of undergoing nom, it must rely on a lexical determiner to satisfy its argumental status. The type shift BE would then be needed to interpret the full structure (Partee 1987):

a. Sue and Jane are [DP writers].

b. Sue is $\left[{ }_{D P}^{*}(a)\right.$ writer].

a. anu aur ramaa $\left[_{N P}\right.$ lekhikaayeN] haiN

Anu and Rama writers are

b. anu $\left[_{D P}(e k)\left[{ }_{N P}\right.\right.$ lekhikaa $\left.]\right]$ hai

Anu a writer is

Since Hindi has NP's of type $<e t>$, they can shift to argumental types $e$ via nom or 
iota in those structures where functional application requires that type. They can also combine with determiners to yield $<<e t>t>$. In copular constructions, however, their basic meaning suffices making the indefinite determiner optional.

Turning to incorporation structures, we may now have a way of making a syntactic distinction between Hindi and English. And this syntactic difference may be tied to a semantic distinction that would separate out incorporation possibilities. If Hindi allows structures like (40a) or (40b), while English only allows (40b), we could say that complex property formation takes place if a transitive verb has a predicative expression as its object. Of course, this would not be forced since I am assuming that it is possible for standard functional application to take place by shifting the bare NP to type $e$ via iota. Note that incorporation structures like (40a) will still allow negation to intervene in incorporation, as desired:
a. [VP [NP lion ] [V see]]
b. [ [VP [DP a [NP lion]] [v see $]]$

One consequence of taking this line and dispensing with kinds in the derivation of incorporated readings is that we can no longer appeal to the notion of well-established kinds to explain the restricted range of modification possible with incorporated bare singulars, shown in (36a)-(36b). But note that the theme suppression story relies on native speakers' perceiving a connection between the incorporated VP meaning and a regular VP meaning. Even if the incorporated meaning was built up out of the predicative meaning of the modified nominal, perhaps the same restrictions could be derived based on the fact that a conventionalized connection is only possible with proto-typical activities. Thus a connection between $\lambda \mathrm{x}[$ old-book-sell(x)] and $\lambda \mathrm{x}[\exists \mathrm{y}[\operatorname{old}(\mathrm{y}) \& \operatorname{book}(\mathrm{y}) \& \operatorname{sell}(\mathrm{x}, \mathrm{y})]$ would be possible, but not between $\lambda x[$ expensive-book-sell $(\mathrm{x})]$ and $\lambda \mathrm{x}[\exists \mathrm{y}[\operatorname{expensive}(\mathrm{y}) \& \operatorname{book}(\mathrm{y}) \& \operatorname{sell}(\mathrm{x}, \mathrm{y})]$.

It goes without saying that the ideas presented in this section are tentative, intended to preserve the key ingredients of incorporation as theme suppression, while attempting to address the problem posed by the version argued for earlier.

\section{Conclusion}

To conclude, the fact that bare nominals and indefinites form a natural class with respect to a number of semantic tests favors a uniform treatment of them by Occam's Razor. This paper, however, has highlighted some differences between them that make Occam's Razor inapplicable. The possibility of reference to kinds, I have argued, is one dimension along which they can be distinguished. In discussing incorporated nominals, I've brought out differences between incorporated and bare nominals and within the class of incorporated nominals, suggesting that theme suppression vs. existential bindng of the theme may be the source of these differences. 


\section{Endnotes}

* Thanks for useful comments to Mark Baker, Maria Bittner, Miriam Butt, Gennaro Chierchia, Regina Eckhart, Klaus von Heusinger, Alan Munn, Cristina

Schmitt, Roger Schwarzschild and the audiences at University of Pennsylvania Colloquium, SALT IX (UCSC) and SURGE, the Rutgers Semantics Group.

1 Hindi has a demonstrative which can combine with nouns or be used by itself as a pronoun. It also allows null pronouns that can have discourse antecedents.

2 As noted in Porterfield and Srivastav 1988, the singular term can get existential readings of a certain type, if accompanied by non-neutral intonation. This is not so for bare plurals. My focus here will be on the difference that is evident with neutral intonation, leaving nuanced existential readings for another occassion.

3 Existential readings of bare singulars will be discussed in section 3. Limitations of space preclude a full discussion of their generic readings here. I will simply note that analyses of singular kinds such as Ojeda 1991 or Chierchia 1998 allow predication to individual members of the singular kind. This has the undesirable consequence of letting in not only generic binding of individual instantiations but also existential binding. One alternative that does not suffer from this problem is to derive such readings via generic quantification over situations, utilizing the iota shifted meaning of the bare nominal. Another is to treat the singular kind as an abstract object, denoting typical and/or representative properties associated with the kind. The choice between these two possibilities requires further discussion, beyond the scope of this paper.

4 To anticipate the discussion in the next section, one might think that the relevant reading of (19a) is due to incorporation, not due to the blocking effect of iota. That this is not the case can be seen by comparing English and Hindi sentences with the bare plural in subject position. Parts of this machine are in that room has an indefinite reading referring to some parts. is mashiin ke Tukre us kamre meN haiN has only the definite reading referring to all the parts.

${ }^{5}$ Mohanan allows ACC and NOM marked objects under VP but only NOM marked objects under V. Thanks to Miriam Butt for discussion of Mohanan 1995.

6 The present characterization of the semantic import of $k o$ is not complete. There are contexts, typically generic contexts, where the definiteness requirement is suspended. Also, inanimate objects are often awkward with ko. At this point, I have not studied the nuances enough to venture any further than this.

${ }^{7}$ Sometimes vo seems somewhat odd even with an indefinite antecedent. Possibly, this is more so with inanimate objects. At this point I do not have the full generalization. The examples in the text use animate objects because pronominal anaphora is fully acceptable when the antecedent is a regular animate indefinite.

\section{References}

Baker, M. 1988. Incorporation: A Theory of Grammatical Function Changing, The University of Chicago Press, Chicago. 
Barker, C. 1992. "Group Terms in English: Representing Groups as Atoms", Journal of Semantics 9, 69-93.

Bittner, M. 1994. Case, Scope and Binding, Kluwer, Dordrecht.

Butt, M. 1993. "Specificity in Hindi/Urdu", in Proceedings of CLS 29, 89-103.

Carlson, G. 1977. Reference to Kinds in English, Ph.D. thesis, UMass.

Chierchia, G. 1998. "Reference to Kinds Across Languages", Natural Language Semantics 6.

Dayal, V. 1992. "The Singular-Plural Distinction in Hindi Generics", Proceedings of SALT II.

Dayal, V. 1998. “Any as Inherently Modal”, Linguistics and Philosophy 21, 433-476.

de Hoop, H. 1992. Case, Configuration and NP Interpretation, Ph.D. Dissertation, Riks Universitaet, Groningen.

Dekker, P. 1993. "Existential Disclosure", Linguistics and Philosophy 16, 561-589.

Diesing, M. 1992. Indefinites, MIT Press, Cambridge.

Dowty, D. 1979. Word Meaning and Montague Grammar, Reidel, Dordrecht.

Enç, M. 1991. "The Semantics of Specificity", Linguistic Inquiry 22, 1-25.

Gerstner, C. and M. Krifka. 1993. "Genericity", in J.Jacobs, A. von Stechow, W. Sternefeld and T. Venneman (eds) Handbuch der Syntax, de Gruyter, Berlin.

Heim, I. 1982. The Semantics of Definite and Indefinite NP's. Ph.D. thesis, UMass. Kamp, H. 1981. "A Theory of Truth and Discourse Representation", in J. Groenendijk, T. Janssen and M. Stokhof (eds.) Formal Methods in the Study of Language, Mathematical Centre, Amsterdam.

Kratzer, A. 1995. "Stage-level and Individual-level Predicates" in Carlson and Pelletier (eds.).

Krifka, M., F.Pelletier, G. Carlson, A. ter Meulen, G. Chierchia and G. Link. 1995. "Genericity: an introduction", in G.Carlson and F.J. Pelletier (eds.) The Generic Book, Chicago: The University of Chicago Press.

Mithun, M. 1984. "The Evolution of Noun Incorporation", Language 60.

Mithun, M. 1986. “On the Nature of Noun Incorporation”, Language 62.

Mohanan, T. 1995. "Wordhood and lexicality", NLLT 13, 75-134.

Ojeda, A. 1991. "Definite Descriptions and Definite Generics", $L \& P 14,367-398$.

Partee, B. 1987. "Noun Phrase Interpretation and Type-Shifting Principles", in J. Groenendijk et al. (eds.) Studies in Discourse Representation Theory and the Theory of Generalized Quantifiers, Foris, Dordrecht.

Porterfield, L. and V. Srivastav. 1988. "Indefiniteness in the absence of articles: evidence from Hindi and Indonesian", Proceedings of WCCFL 7.

Ramchand, G. 1997. Aspect and Predication: The Semantics of Argument Structure, Oxford University Press, Oxford.

Sadock, J. 1986. "Some Notes on Noun Incorporation", Language 62.

Schwarzschild, R. 1996. Pluralities, Kluwer, Dordrecht.

Van Geenhoven, V. 1996. Semantic Incorporation and Indefinite Descriptions, Ph.D. Dissertation, University of Tuebingen.

Wilkinson, K. 1991. Studies in the Semantics of Generic NP's, Ph.D. thesis, UMass. 